This item was submitted to Loughborough's Research Repository by the author.

Items in Figshare are protected by copyright, with all rights reserved, unless otherwise indicated.

\title{
Investigation of the electro-spinnability of alginate solutions containing gold precursor $\mathrm{HAuCl} 4$
}

PLEASE CITE THE PUBLISHED VERSION

http://dx.doi.org/10.1016/j.jcis.2016.08.037

\section{PUBLISHER}

(C) Elsevier

VERSION

AM (Accepted Manuscript)

\section{PUBLISHER STATEMENT}

This work is made available according to the conditions of the Creative Commons Attribution-NonCommercialNoDerivatives 4.0 International (CC BY-NC-ND 4.0) licence. Full details of this licence are available at: https://creativecommons.org/licenses/by-nc-nd/4.0/

\section{LICENCE}

CC BY-NC-ND 4.0

\section{REPOSITORY RECORD}

Anyfantis, George C., Hadi Hajiali, Elisa Mele, Sergio Marras, Riccardo Carzino, Lara Marini, Evie L. Papadopoulou, and Athanassia Athanassiou. 2016. "Investigation of the Electro-spinnability of Alginate Solutions Containing Gold Precursor Haucl4”. figshare. https://hdl.handle.net/2134/23184. 
Investigation of the electro-spinnability of alginate solutions containing gold precursor $\mathrm{HAuCl}_{4}$.

George C. Anyfantis*a,b, Hadi Hajiali ${ }^{\mathrm{b}}$, Elisa Mele*b, Sergio Marras ${ }^{\mathrm{c}}$, Riccardo Carzino $^{\mathrm{b}}$, Lara Marini ${ }^{\mathrm{b}}$, and Athanassia Athanassiou* ${ }^{\mathrm{b}}$

${ }^{\text {a }}$ Department of Inorganic Chemistry, Faculty of Chemistry, University of Athens, Panepistimiopolis Zografou, Athens 15771, Greece

${ }^{\mathrm{b}}$ Smart Materials, Nanophysics, Istituto Italiano di Tecnologia, Via Morego, 30 16163 Genova, Italy

${ }^{\mathrm{c}}$ Nanochemistry, Istituto Italiano di Tecnologia, Via Morego, 30 - 16163 Genova, Italy

Corresponding authors at: Smart Materials, Nanophysics, Istituto Italiano di Tecnologia, Via Morego, 30 - 16163 Genova, Italy. Tel.: +39 010 71781414; fax: +3901071781236

*E-mail: anyfantisgc@chem.uoa.gr

*E-mail: athanassia.athanassiou@iit.it

*E-mail: e.mele2@1boro.ac.uk Current Address Department of Materials, Loughborough University, Epinal Way, Loughborough, LE11 3TU, United Kingdom.

Keywords: Nano-fibers, sodium alginate, gold nanoparticles.

\section{Abstract}


Alginate nanofibers with an average diameter of $75 \mathrm{~nm}$ have been prepared by the electrospinning process. In addition, the spinnability of the solutions in the presence of the gold precursor $\mathrm{HAuCl}_{4}$ was investigated. At low concentrations of $\mathrm{HAuCl}_{4}$ well-formed nanofibers were produced, whereas as its concentration increases the nanofibrous mats present an increased number of bead-like defects. Herein, the in situ preparation of gold nanoparticles (Au NPs) is discussed since sodium alginate (SA) acts as the reducing agent and a mechanism is proposed in order to explain the beadeffect as well as the surface morphology of the alginate fibers decorated with Au NPs.

\section{Introduction}

Owning a significantly high surface to volume ratio, nanofibers produced by electrospinning can be used in various sectors, including catalysis, sensing, electronics, optics, filtration and biotechnology[1-5]. Electrospinning is an ideal method for generating fibers with diameter in the nano-range. The smaller diameter of fibers results in higher surface to volume. The entanglement of the nanofibers leads the formation of a three dimensional nonwoven mat with high density of pores which is fully accessible to chemical species. Applications of these nanostructures necessitate the preparation of well-defined fibers with controlled nano-topographies. Currently, tremendous scientific attention has been devoted towards the enhancement of the properties of these electrospun structures by combining them with different classes of nanoparticles (NPs), leading to advanced fibrous nanocomposites[2], [6-9]. The major methods for the preparation of NPs-electrospun fibers can be categorized in the direct fabrication during electrospinning process and the indirect fabrication after electrospinning process. In the first case the as-prepared NPs are dispersed into 
the solution before the electrospinning process, whereas in the second case the NPs are introduced after the electrospinning process. The presence of precursors or NPs into the polymer solution affects various parameters, like viscosity and conductivity, which have to be taken into account during the electrospinning process[6].

Especially, when precursors are involved in the preparation of metal NPs-electrospun fibers (Au, Ag, Pd etc.)[10-13] an additional step of reduction is involved. Metal NPselectrospun fibers addressing bio-applications must fulfil some conditions, such as biocompatibility and biodegradability and absence of toxic chemicals during the reduction step. Alginate, as a natural polymer[14-16] has been frequently used in a plethora of research activities in the biomedical field. One disadvantage of alginate is that it cannot be electrospun on its own[17-19]. Nevertheless, blends of alginate with other polymers, such as polyethylene oxide (PEO)[17], [20], [21], can circumvent this limitation. Furthermore, chemically modification of the alginate nanofibers by incorporation with Au NPs addressing the biomedical usage of the nonwowen mats. The additional gold surfaces intended to facilitate cellular adhesion and proliferation. Herein, we show the preparation of alginate nanofibers by electrospinning solutions of SA-PEO-Pluronic F127 (PF127) and we investigate the spinnability of those solutions in the presence of the gold precursor $\mathrm{HAuCl}_{4}$. In addition, the in situ preparation of $\mathrm{Au}$ NPs is discussed since SA acts as the reducing agent. Overall, we present a green procedure for the fabrication of Au NPs-electrospun fibers.

\section{Materials and methods}

\subsection{Materials}


Alginic acid sodium salt from brown algae (Mw 120-190 kDa and M/G ratio 1.56), poly (ethylene oxide) $\left(\mathrm{M}_{\mathrm{w}} 600 \mathrm{kDa}\right)$, Pluronic F127 and gold(III) chloride trihydrate (99.9\%) were purchased from Aldrich, and were used without further purification. For the preparation of the aqueous solutions we used Milli-Q double distilled water (resistivity $>18.2 \mathrm{M} \Omega \mathrm{c}$ ).

\subsection{Electrospinning of alginate blends}

The components of our electrospinning set up were i) a syringe pump (NE-1000, New Era Pump Systems, Inc.), high-voltage power supply (EH40R2.5, Glassman High Voltage, Inc.) and a aluminium grounded collector plate. The solutions were electrospun through a 23-gauge needle. The distance between the needle tip and the collector was $20 \mathrm{~cm}$. The voltage was of $20 \mathrm{kV}$, with slight variation until a stable Taylor cone has been formed. All experiments were carried out at room temperature $\left(22-26{ }^{\circ} \mathrm{C}\right)$ and with relative humidity $45-55 \%$. The procedure to prepare solutions containing SA/PEO/PF127 (4.0/1.5/1.0 \%w/v) was: SA, PEO and PF127 were dissolved into $9 \mathrm{~mL}$ of water by stirring for two days, then $1 \mathrm{~mL}$ of water was added and the final solution was stirred vigorous for $2 \mathrm{~min}$. For blends with DMF, $0.5 \mathrm{~mL}$ of DMF were mixed with $1 \mathrm{~mL}$ of water and then added to the solution. For the preparation of the solutions containing the gold precursor the same procedure was followed but for the last step the appropriate amount of gold precursor was added into $1.5 \mathrm{~mL}$ of $\mathrm{H}_{2} \mathrm{O} / \mathrm{DMF}$. The electrospinning was carried out immediately after the preparation of the solutions. All experiments performed three times to evaluate the reproducibility of our procedure. 


\section{Characterization techniques and instruments}

Nanofiber mats were analyzed with High Resolution Scanning Electron Microscopy (HRSEM) using a JEOL JSM 7500FA, equipped whit a cold field emission gun (single crystal tungsten $<310>$ emitter, ultimate resolution of $1 \mathrm{~nm}$ ) and operating at $5 \mathrm{kV}$ in secondary electron (SE) and backscattered electron (BSE) imaging mode. Fiber diameters were estimated using the program ImageJ. Fourier transform infrared (FT-IR) spectra were recorded by a VERTEX 70 FT-IR spectrometer, in the range 4000-600 $\mathrm{cm}^{-1}$. TGA measurements were carried out on a Q500 TA apparatus (TA Instruments, USA). An air flow with a rate of $50 \mathrm{~mL} / \mathrm{min}$, a heating rate of $5{ }^{\circ} \mathrm{C} / \mathrm{min}$ and platinum pans were used. The samples were analyzed from $30^{\circ} \mathrm{C}$ to $600^{\circ} \mathrm{C}$. Ionic conductivity measurements were carried out using a potentiostat (Mettler Toledo) equipment with a 4 cell graphite type conductivity sensor operating in the range 0.01 $200 \mathrm{mS} / \mathrm{cm}$. The surface tension kinetic measurements were performed with a Dataphysics OCAH200 contact angle instrument equipped with a 2/3" CCD Chip camera. The surface tension was evaluated through the pendant drop method following the evaporation kinetic of a $14 \mu$ d drop of the different solutions at ambient temperature. For the calculation the Young-Laplace equation was used.

\section{Results and discussion}

\subsection{Preparation of alginate nanofibers}

We prepared SA/PEO/PF127 aqueous solution with a concentration of 4.0/1.5/1.0 $\% \mathrm{w} / \mathrm{v}$ (or $61.54 / 23.08 / 15.38 \% \mathrm{wt}$ mass concentration). In fact, it is well-documented 
that the fabrication of SA nanofibers requires the use of PEO and PF127 in order to increase the entanglement of the polymer chains through new formed hydrogen bonds between SA and PEO[21]. Fig. 1a shows that despite the presence of PEO and PF127 the obtained electrospun mats were characterized by nano-filaments connected with beaded structures. In order to circumvent the bead-effect we added $5 \% \mathrm{v} / \mathrm{v}$ of dimethylformamide (DMF) as co-solvent in the polymeric solution. The blend with DMF resulted in well-structured nanofibers that were free from defects, like beads or droplets (Fig. 1b). The produced nanofibers exhibited an average diameter of $75 \mathrm{~nm}$ (Fig. S1 in Supporting Information). DMF, like dimethyl sulfoxide (DMSO) is a highly polar solvent (dipole moment $3.86 \mathrm{D}$ ) miscible in water, and it interacts with the SA chains through dipole-dipole bonds weakening their interaction[18], [22], [23]. In addition, the presence of DMF lowers essentially the ionic conductivity (Fig. S2 in Supporting Information).
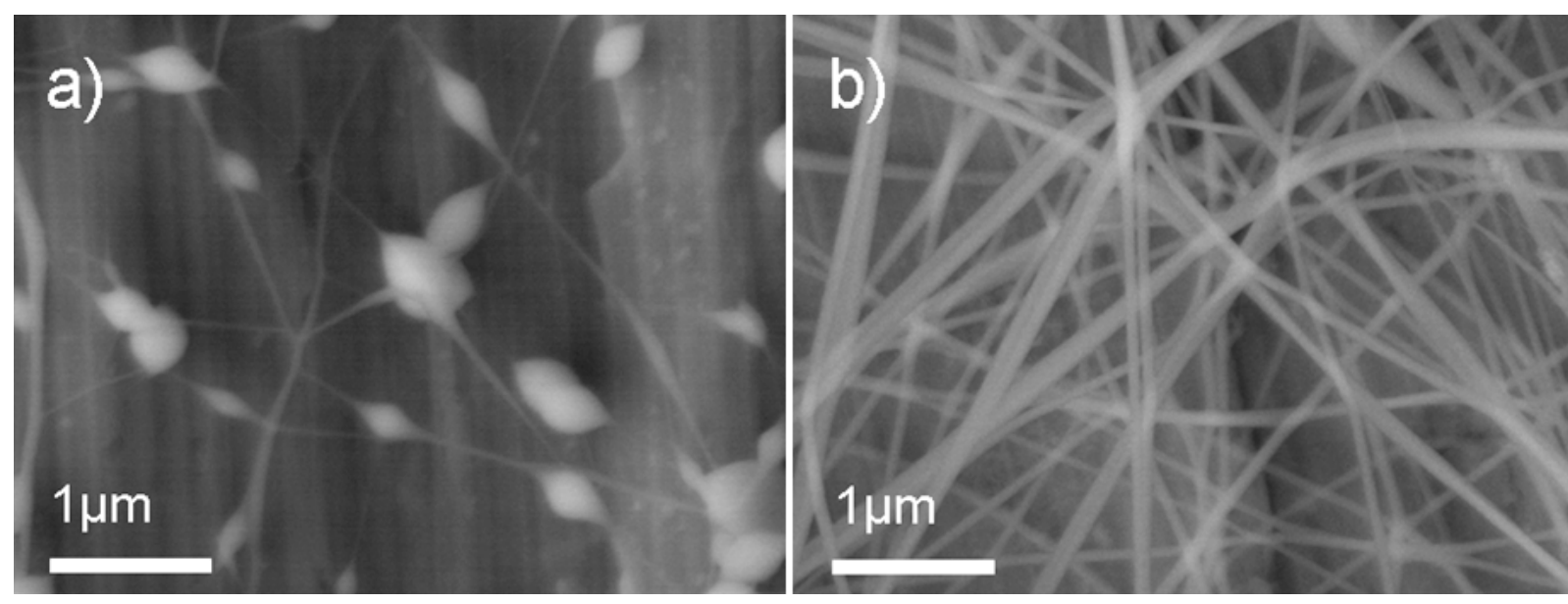

Fig. 1. High-resolution scanning electron microscope (HRSEM) images of the nanofibers obtained from aqueous solution of SA/PEO/PF127 with concentration 4.0/1.5/1.0 \%w/v a) without DMF and b) with DMF. The solutions have a volume of $10 \mathrm{~mL}$. The addition of DMF was $0.5 \mathrm{~mL}$. 


\subsection{Variations in gold anions concentration}

With the aim to investigate how the degree of complexation of SA chains with gold anions[14], [24-27] affects the electrospinning process, we prepared SA/PEO/PF127 solutions containing different concentrations of gold precursor $\left(\mathrm{HAuCl}_{4}\right): \mathrm{Au} / \mathrm{SA}$ mass ratio of 0.0025 (sample A1), 0.0050 (sample A2), 0.0075 (sample A3), and 0.0150 (sample A4). Table 1 summarizes the experimental parameters and the physicochemical properties of the solutions. The interactions between SA and PEO were monitored by FT-IR spectroscopy[28], [29], which is a powerful tool in this case due to the different chemical structure of the three polymers used (SA is rich in carboxylic groups, and its FT-IR spectrum is characterized by the bands assigned to $\mathrm{COO}^{-}$vibrations; (see Fig. S3 in Supporting Information). Comparing the spectrum from a film without DMF and gold anions with the spectrum from a film obtained from solution A4 (with DMF and the highest concentration in gold anions) we observed differences due to the interaction of DMF with the SA chains and their complexation with the gold anions (see Fig. 2). The symmetric $\mathrm{COO}^{-}$stretching vibration $\left(v(\mathrm{COO})_{\mathrm{sym}}\right)$ shifts to higher frequencies due to the presence of the gold precursor (from 1411 to $1415 \mathrm{~cm}^{-1}$ ); this peak is specific for ionic binding proving the new Au-carboxylate bonding[24], [26]. In addition the $v(\mathrm{OH})$ peak becomes narrower and of higher intensity[28]. The characteristic change of the $v(\mathrm{OH})$ peak indicates an increase in intramolecular bonding as a consequence of two factors: a) the complexation of gold and b) the hydrogen bonds created after the insertion of DMF. 

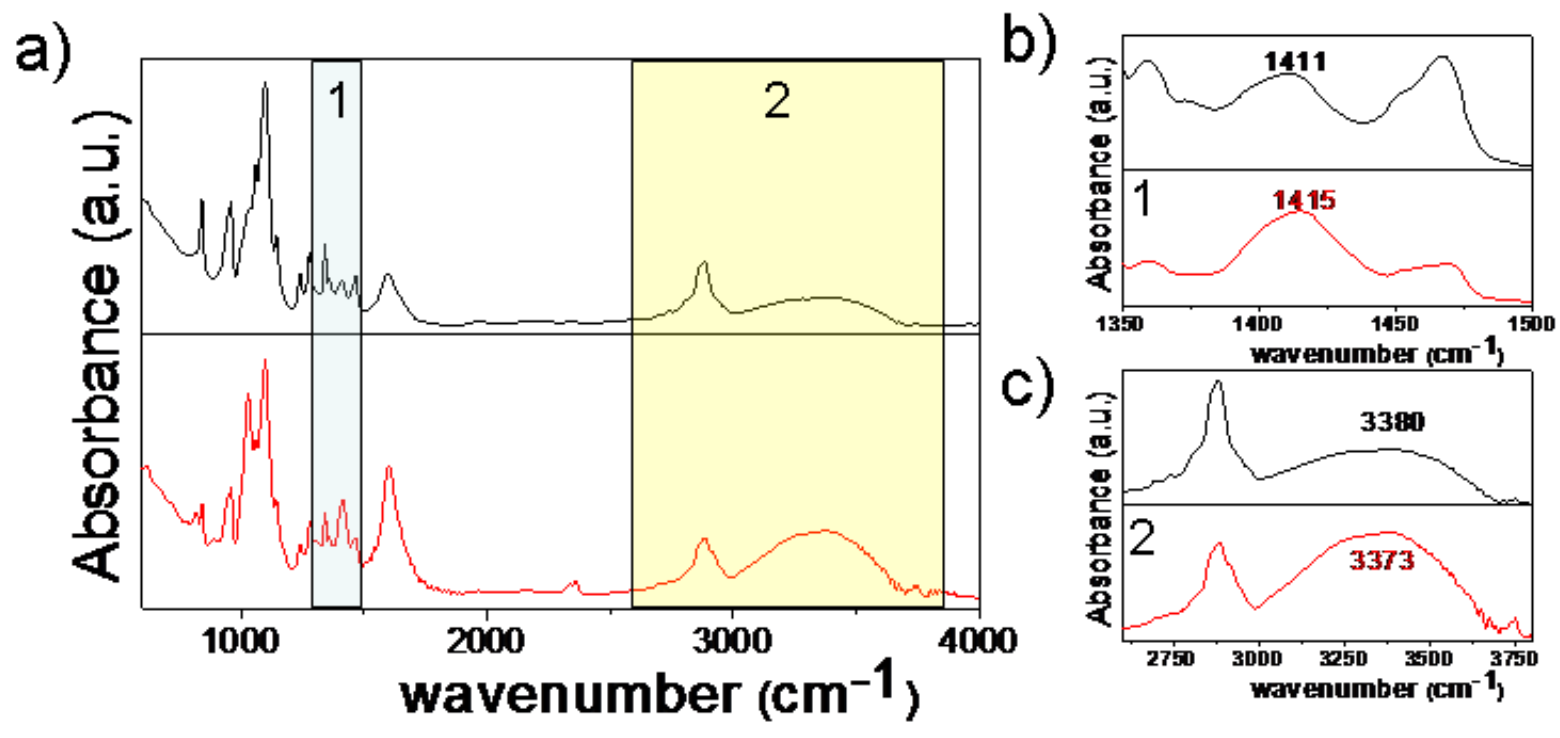

Fig. 2. FT-IR spectra of films prepared from an aqueous solution of SA/PEO/PF127 with a concentration of 4.0/1.5/1.0\%w/v (black line) and from the solution A4 (red line). The most characteristic bands are the band 1 which corresponds to the $v\left(\mathrm{COO}^{-}\right.$ )$_{\text {sym }}$ vibration and the band 2 which corresponds to the $v(\mathrm{OH})$ vibration. Graphs $\mathrm{b}$ ) and c) show the regions $\mathbf{1}$ and 2, respectively in higher magnification for comparison reasons.

Table 1. Experimental parameters and the physicochemical properties of the solutions

\begin{tabular}{cccccc}
\hline Sample & Mass & Mass ratio & Conductivity & Surfase & Morphology \\
& SA/PEO/PF127/Au & Au/SA & $\begin{array}{c}\text { Tension } \\
{[\mathrm{mS} / \mathrm{cm}]}\end{array}$ & of the mat \\
& $400 / 150 / 100 / 0$ & 0 & 5.1 & 39.5 & fibers \\
\hline A0 & $400 / 150 / 100 / 1$ & 0.0025 & 4.8 & 41.5 & fibers \\
A1 & $400 / 150 / 100 / 2$ & 0.0050 & 4.9 & 41.2 & fibers with beads \\
A2 & $400 / 150 / 100 / 3$ & 0.0075 & 5.1 & 40.8 & fibers with beads \\
A3 & & & & &
\end{tabular}


Examination by HRSEM (Fig. 3) revealed that the electrospun mats prepared from the solutions A1 (lowest concentration of gold precursor) consisted from well-formed nanofibers without defects. The fibers have an average size of $c a .90 \mathrm{~nm}$ (Fig. S1 in Supporting Information). The increase of the amount of the gold anions affects the morphology of the mats and beads start to appear. Upon electrospinning of the solutions A2 spindle-like beads appear (Fig. 3b), while with further increase of the gold precursor the morphology of the beads changes (Fig. 3c and 3d) from spindlelike to spherical (solutions A4).

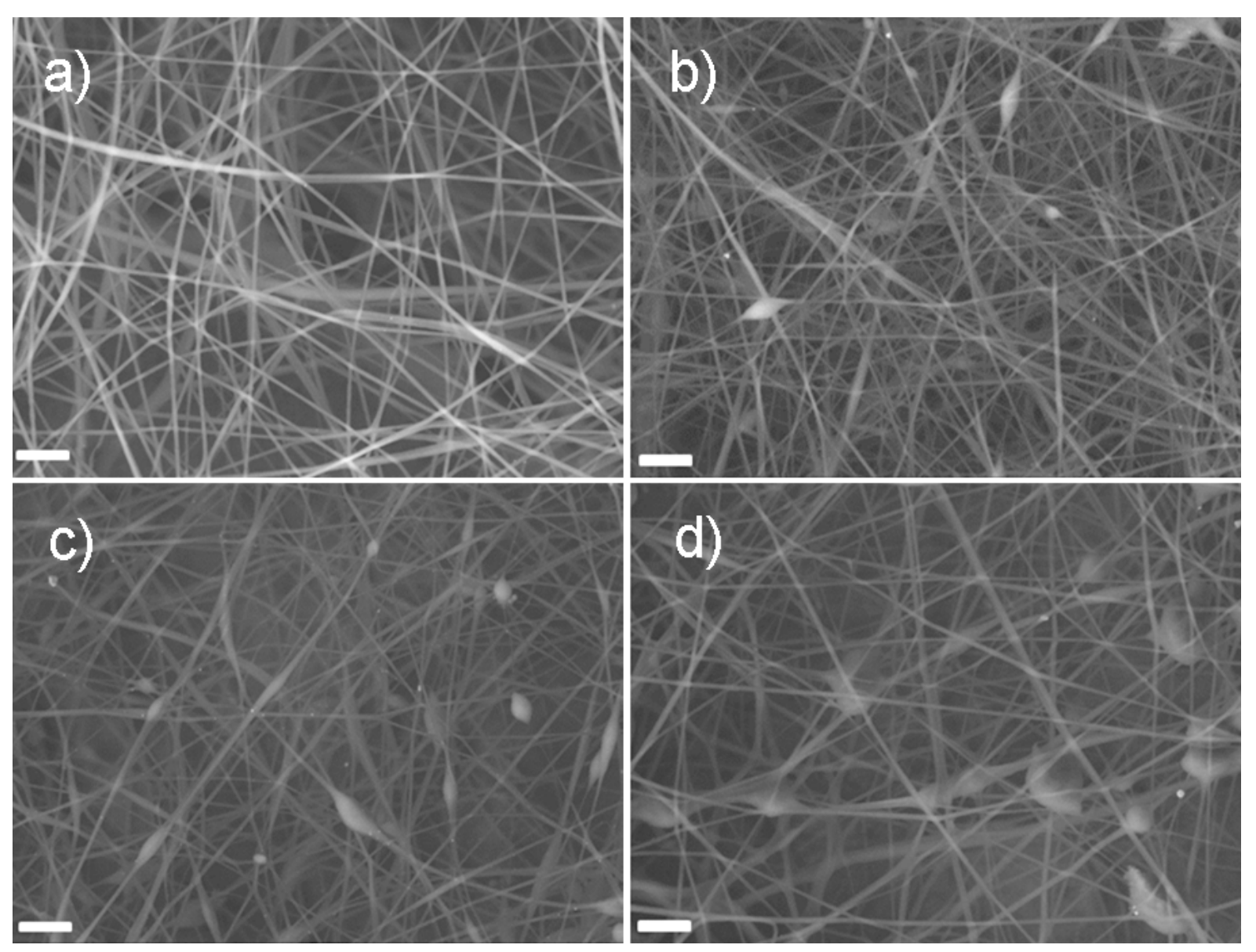


Fig. 3. a) HRSEM images for the nanofibers obtained from the aqueous solution a) A1, b) A2, c) A3 and d) A4. All solutions have a volume of $10 \mathrm{~mL}$ and the addition of DMF was $0.5 \mathrm{~mL}$. Scale bar is $1 \mu \mathrm{m}$.

\subsection{Spinnability versus concentration of gold anions}

The complexation of small amounts of anions does not affect the spinnability of our system. The bead-effect becomes more intense as the amount of the gold anions becomes higher, indicating that the presence of gold anions affects the electrospinning, although the changes that the gold anions induce to the conductivity and surface tension of the solutions (see Table 1) are minimal. Comparing, for example, solution A3 with the solution A0 we observed that the conductivity values are identical $(5.10 \mathrm{mS} / \mathrm{cm})$ and the surface tension values are very close $(39.53$ and $40.78 \mathrm{mN} / \mathrm{m}$ for $\mathbf{A 0}$ and A3, respectively). Nevertheless, solutions A3 provide mats with beads. The presence of the gold anions into the polymer blends is the main reason for the alternation on the spinnability behaviour. Fig. 4 shows the surface tension kinetics performed on the samples suggesting a gradual decrease during the electrospinning process. The surface tension values in all samples with gold anions decrease with the decreasing factor to be bigger on the samples with the higher amount of gold anions. 


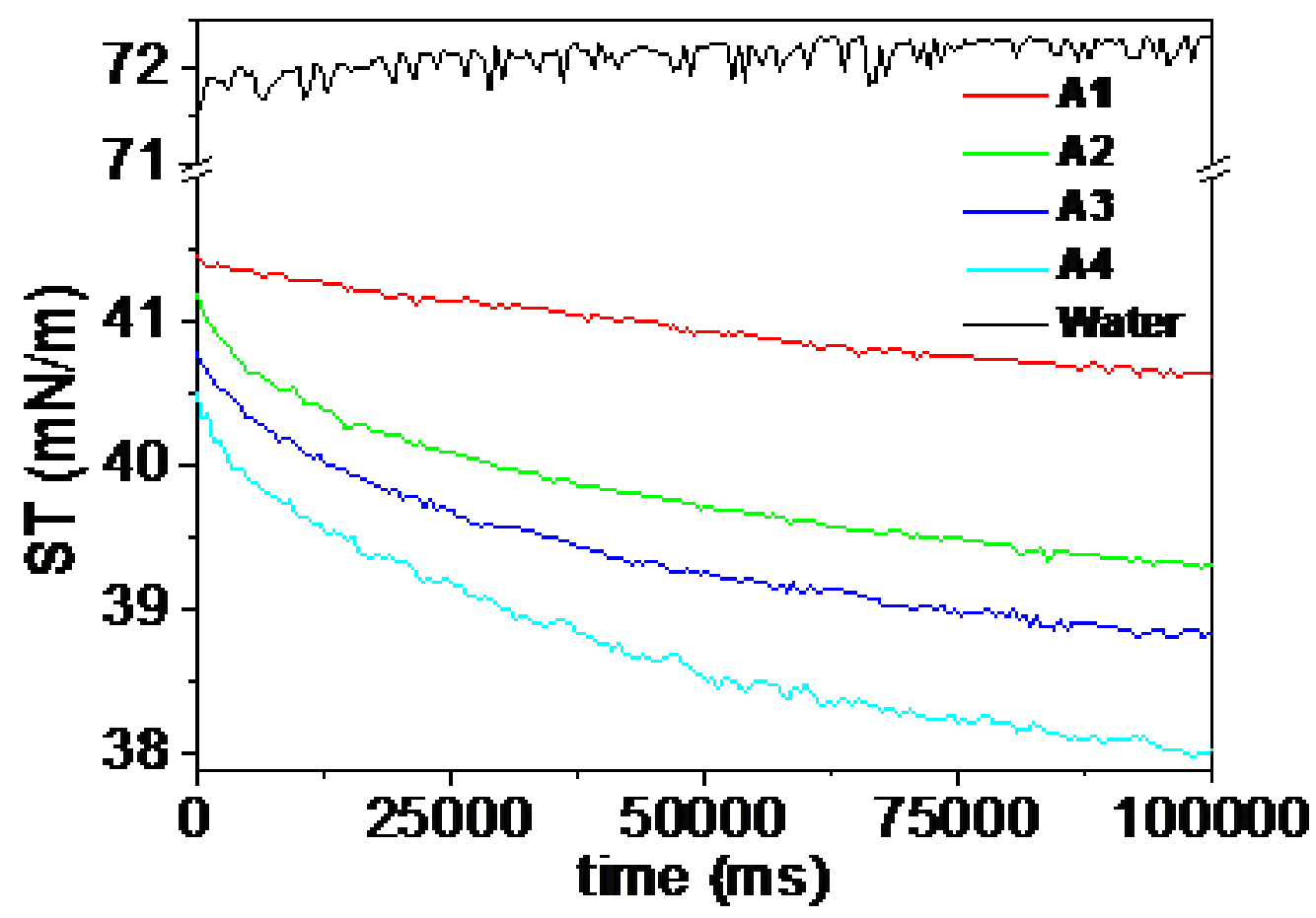

Fig. 4. Surface tension kinetics performed for the aqueous solution a) A1, b) A2, c) A3 and d) A4.

Therefore, the bead-effect most likely depends also on the complexation of the alginate chains with Au anions. Alginate is a linear polysaccharide that features 1,4linked $\beta$-D-mannuronic (M) and $\alpha$-L-guluronic $(\mathrm{G})$ acid residues. In alginate, $\mathrm{G}$ and $\mathrm{M}$ units are arranged in a non-regular sequence and occur as $(\mathrm{M})_{\mathrm{x}},(\mathrm{G})_{\mathrm{x}}$ and $(\mathrm{MG})_{\mathrm{x}}$ blocks, with a zigzag configuration[14]. Usually, the $(\mathrm{G})_{\mathrm{x}}$ blocks are considered the main centres for complexation. Therefore, when we introduce gold anions $\left[\mathrm{AuCl}_{4}\right]^{-}$ the polymer net most probably undergoes a new arrangement due to the selective complexation of the $\left[\mathrm{AuCl}_{4}\right]^{-}$on the $\mathrm{G}$ units. Even more, as it is well described by the egg-box model[30], [31], through an inter-chain dimerization, alginate creates cavities suitable for strong binding with anions. We believe that this kind of linkage between 
two or more alginate chains is the main reason for the bead-effect, since the new arrangement brings more alginate chains together and destroys their entanglement with the PEO chains. Alginate chains act as strong ligands and they are attached strongly to the surface of the AuNPs. These observations are in accordance with the results obtained from FT-IR measurements (see Fig.2), monitoring the new Aucarboxylate bonding formed after the complexation of the gold anions with the SA chains. The effect is disturbance of the entanglement between polymers, which results into defects during electrospinning. Furthermore the migration of SA chains due the applied electric field is an additional factor which leads to a new rearrangement for the polymers. As the polymer solution passes through the needle, during the electrospinning process, negatively charged species are attracted to the positively charged electric field on the needle walls[20]. Thus, alginate, a negatively charged polyelectrolyte, is preferentially distributed on the outer surfaces of the electrospun fibers, whereas PEO preferentially remains within the interior. This effect becomes stronger when the gold ions are introduced to the solution, with the gold anions which are chemically bonded with the alginate chains (complexation into the guluronic blocks) to be directed to the outer surfaces of the electrospun fibers. The proposed mechanism is schematically presented in Scheme 1. 


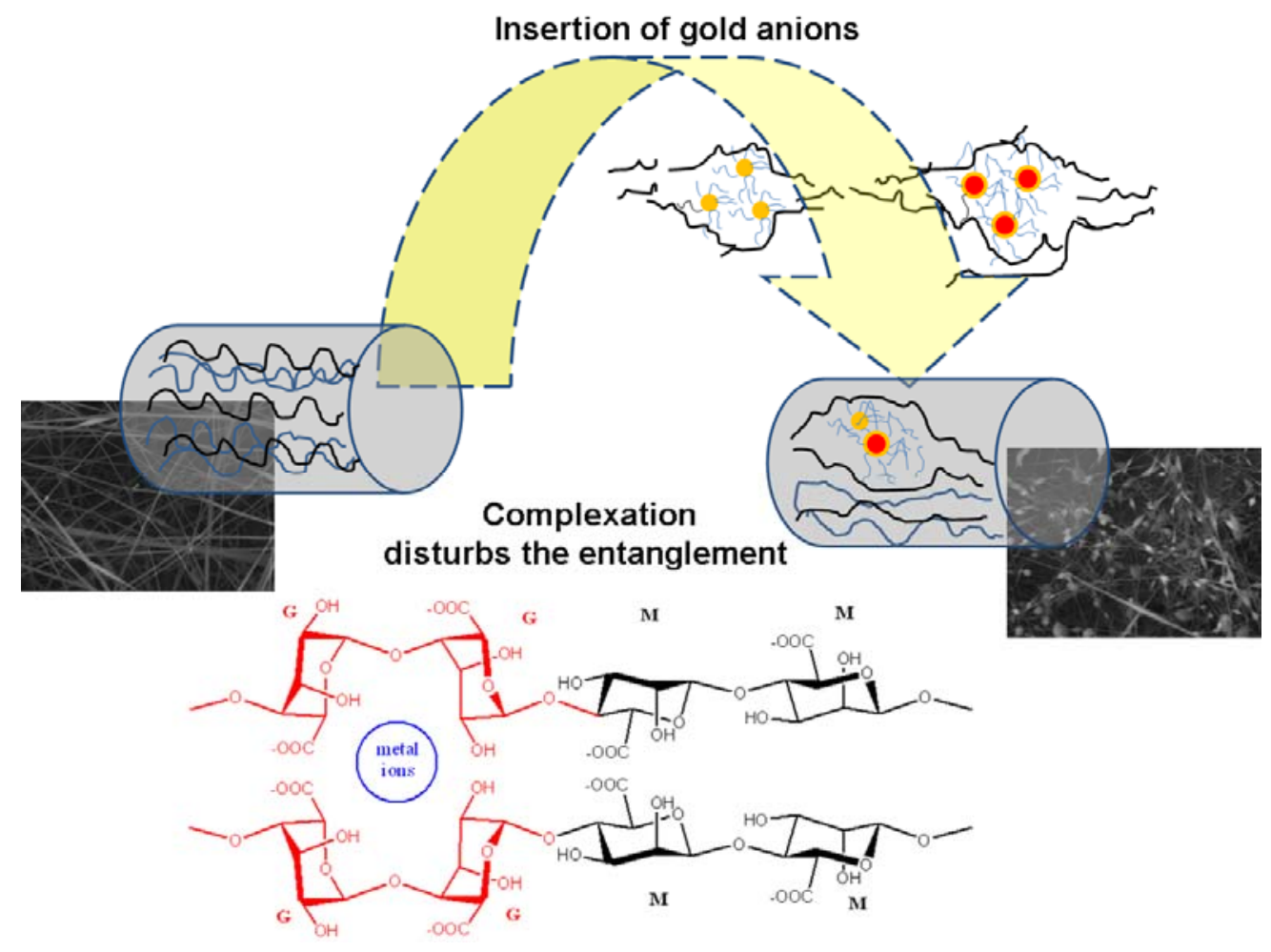

Scheme 1. Schematic representation for the proposed mechanism which explains the bead-effect. The gold anions and Au NPs through complexation with the alginate chains destroy the entanglement which was succeeded between SA and PEO chains. The molecular structure of alginate polymer shows that the cavities formed by the $G$ units interact with metal ions.

\subsection{Formation of gold nanoparticles}

As aforementioned the solutions with gold precursor are capable to form nanofibers. Next we investigate the chemical nature of $\left[\mathrm{AuCl}_{4}\right]^{-}$anions in the formed nanofibers in order to clarify whether they form Au NPs or they remain unchanged. The reduction of $\left[\mathrm{AuCl}_{4}\right]^{-}$to $\mathrm{Au}$ NPs into the alginate solutions is a procedure not clearly defined due to various factors that can act as reducing agents[24], [32-34]; light (laboratory conditions), water, PEO and alginate, which are rich in carboxyl and 
hydroxyl groups, can promote gold reduction. Since all solutions were electrospun 2 minutes after the addition of gold precursor probably some Au NPs already form during the preparation of the solutions for electrospinning. Fig. 5a shows a HRSEM image of the mat obtained from the aqueous solution A4 (highest concentration in gold precursor). The population of $\mathrm{Au}$ NPs in the fibers is extremely low and it remains the same even after days, indicating that the reduction of the gold precursor during the electrospinning procedure is poor and it gets significantly minimized due to solvents' evaporation
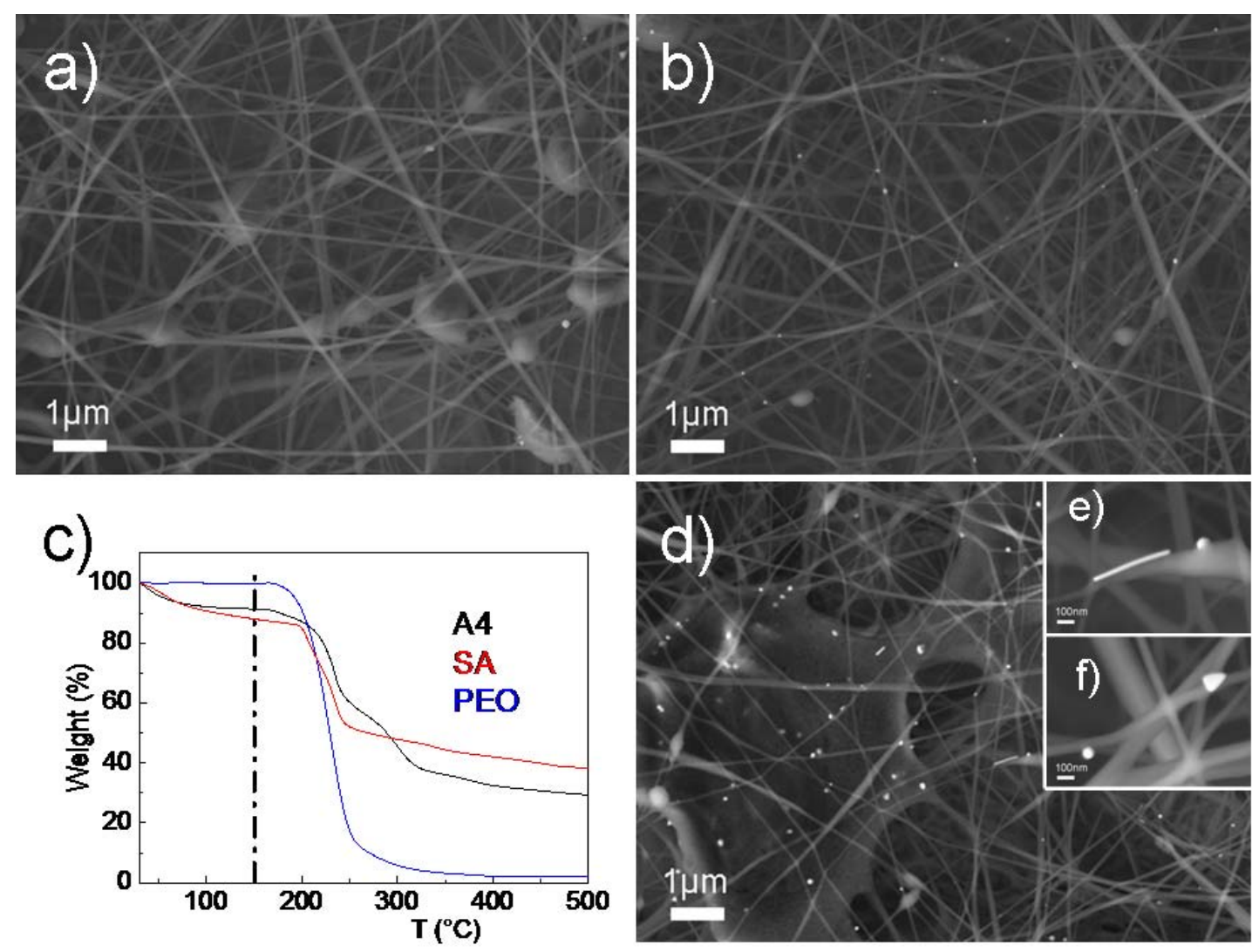

Fig. 5. a) HRSEM image from a mat obtained from a solution A4, b) after thermal treatment for 12 hours at $100{ }^{\circ} \mathrm{C}$. c) TGA measurements obtained for fibers from solution A4 and for the polymers SA and PEO. d) HRSEM image from a mat 
obtained from a solution $\mathbf{A} 4$ after thermal treatment for 12 hours at $150{ }^{\circ} \mathrm{C}$. e) and f) HRSEM images in higher magnification in which it is obvious that the formed $\mathrm{Au}$ NPs are exposed onto the surface of the fibers.

In order to continue the reduction and form a higher amount of Au NPs, the prepared mats were heat treated in an oven at 100 and $150{ }^{\circ} \mathrm{C}$ for a period of 12 hours. In both cases we observed increased number of Au NPs on the surface of the nanofibers. The reason why the maximum heating temperature was set to $150{ }^{\circ} \mathrm{C}$ was that SA upon thermal treatment[35] in air presents a dehydration step (approximately, from 28 up to $177^{\circ} \mathrm{C}$ ) and after a decomposition stage (Fig. $5 \mathrm{c}$ ). At $150{ }^{\circ} \mathrm{C}$ the fibers suffer a small deformation (Fig. 5d), but the heating step does not significantly affect the integrity of the fibers. The small degree of deformation during the heating process was investigated in all samples (see Fig. S4 in Supporting Information) The dehydration could be the main reason for the continuation of the reduction. Most likely, inside the confinement volume of the fibrous net the movement of water molecules puts gold anions in motion and forces them to reduce. Furthermore, it is clear, from Fig. 5e and 5f that the prepared Au NPs (after the heat process) are mainly exposed onto the surface of the fibers creating evident domains. This observation is the consequence of the preferential migration of the negatively charged [AuCl4]- anions on the outer surfaces of the fibers by applying the electric field.

\section{Conclusions}

In conclusion, the preparation of alginate nanofibers by electrospinning SA/PEO/PF127 solution blends is reported. Characterization of the fibers by HRSEM 
revealed an average diameter of $c a .75 \mathrm{~nm}$. In our best knowledge this value of diameter is one of the smallest reported. The electrospun mats consist of nano-fibers with no defects such as beads or droplets. The spinnability of our system was investigated in presence of gold anions. The purpose of this research is to investigate the behaviour of the electrospun polymer blend during the in situ reduction of gold anions and how this affects the morphology of the asprepared nanofibers. At low concentrations of gold anions well-formed nanofibers were produced, but as the concentration increase, the complexation of the gold anions with the alginate chains affects the system and finally the mats present an increased number of beads. A proposed mechanism was discussed in order to explain the bead-effect as well as the surface morphology of the alginate fibers decorated with Au NPs. The gold precursor through an in situ reduction during heating of the formed fibers, forms Au NPs protruding out the surface of the fibers. The bio-compatibility of alginate makes these kind of systems suitable for bio-applications and the protruding Au NPs might act as centres for better cell adhesion and proliferation. These observations paved the way for future work, such as the preferential adhesion of cells on the surfaces of the Au NPs.

References

[1] B. Sun, Y.Z. Long, H.D. Zhang, M.M. Li, J.L. Duvail, X.Y. Jiang, H.L. Yin, Advances in three-dimensional nanofibrous macrostructures via electrospinning,

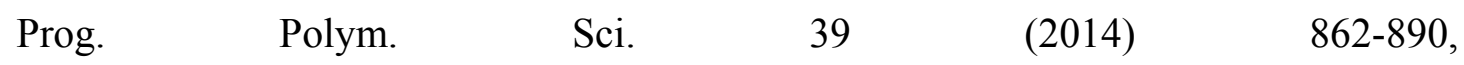
http://dx.doi.org/10.1016/j.progpolymsci.2013.06.002 
[2] D. Li, Y. Xia, Electrospinning of Nanofibers: Reinventing the Wheel?, Adv. Mater. 16 (2004) 1151-1170, http://dx.doi.org/10.1002/adma.200400719

[3] J. Wu, N. Wang, Y. Zhao, L. Jiang, Electrospinning of multilevel structured functional micro-/nanofibers and their applications, J. Mater. Chem. A 1 (2013) 72907305, http://dx.doi.org/10.1039/C3TA10451F

[4] Y. Zhang, J.J. Kim, D. Chen, H.L. Tuller, G.C. Rutledge, Electrospun Polyaniline Fibers as Highly Sensitive Room Temperature Chemiresistive Sensors for Ammonia and Nitrogen Dioxide Gases, Adv. Funct. Mater. 24 (2014) 4005-4014, http://dx.doi.org/10.1002/adfm.201400185

[5] S. Wang, F. Zheng, Y. Huang, Y. Fang, M. Shen, M. Zhu, X. Shi, Encapsulation of Amoxicillin within Laponite-Doped Poly(lactic-co-glycolic acid) Nanofibers: Preparation, Characterization, and Antibacterial Activity, ACS Appl. Mater. Interfaces 4 (2012) 6393-6401, http://dx.doi.org/10.1021/am302130b

[6] C.-L. Zhang, S.-H. Yu, Nanoparticles meet electrospinning: recent advances and future prospects, Chem. Soc. Rev. $43 \quad$ (2014) 4423-4448, http://dx.doi.org/10.1039/C3CS60426H

[7] C.-L. Zhang, K.-P. Lv, H.-P. Cong, S.-H. Yu, Controlled Assemblies of Gold Nanorods in PVA Nanofiber Matrix as Flexible Free-Standing SERS Substrates by Electrospinning, Small 8 (2012) 648-653, http://dx.doi.org/10.1002/smll.201102230 [8] Y. Yu, L. Gu, C. Zhu, P.A. van Aken, J. Maier, Tin Nanoparticles Encapsulated in Porous Multichannel Carbon Microtubes: Preparation by Single-Nozzle Electrospinning and Application as Anode Material for High-Performance Li-Based Batteries, J. Am. Chem. Soc. $131 \quad$ (2009) 15984-15985, http://dx.doi.org/10.1021/ja906261c 
[9] D. He, B. Hu, Q.-F. Yao, K. Wang, S.-H. Yu, Large-Scale Synthesis of Flexible Free-Standing SERS Substrates with High Sensitivity: Electrospun PVA Nanofibers Embedded with Controlled Alignment of Silver Nanoparticles, ACS Nano 3 (2009) 3993-4002, http://dx.doi.org/10.1021/nn900812f

[10] J. Wang, H.-B. Yao, D. He, C.-L. Zhang, S.-H. Yu, Facile Fabrication of Gold Nanoparticles-Poly(vinyl alcohol) Electrospun Water-Stable Nanofibrous Mats: Efficient Substrate Materials for Biosensors, ACS Appl. Mater. Interfaces 4 (2012) 1963-1971, http://dx.doi.org/10.1021/am300391j

[11] D. Li, J.T. McCann, M. Gratt, Y. Xia, Photocatalytic deposition of gold nanoparticles on electrospun nanofibers of titania, Chem. Phys. Lett. 394 (2004) 387391, http://dx.doi.org/10.1016/j.cplett.2004.07.044

[12] A.C. Patel, S. Li, C. Wang, W. Zhang, Y. Wei, Electrospinning of Porous Silica Nanofibers Containing Silver Nanoparticles for Catalytic Applications, Chem. Mater. 19 (2007) 1231-1238, http://dx.doi.org/10.1021/cm061331z

[13] M.M. Demir, M.A. Gulgun, Y.Z. Menceloglu, B. Erman, S.S. Abramchuk, E.E. Makhaeva, A.R. Khokhlov, V.G. Matveeva, M.G. Sulman, Palladium Nanoparticles by Electrospinning from Poly(acrylonitrile-co-acrylic acid)-PdCl2 Solutions. Relations between Preparation Conditions, Particle Size, and Catalytic Activity, Macromolecules, 37 (2004) 1787-1792, http://dx.doi.org/10.1021/ma035163x

[14] T.A. Davis, B. Volesky, A. Mucci, A review of the biochemistry of heavy metal biosorption by brown algae, Water Res. 37 (2003) 4311-4330, http://dx.doi.org/10.1016/S0043-1354(03)00293-8

[15] S.N. Pawar, K.J. Edgar, Alginate derivatization: A review of chemistry, properties and applications, Biomater. $33 \quad$ (2012) 3279-3305, http://dx.doi.org/10.1016/j.biomaterials.2012.01.007 
[16] H. Zheng, Interaction mechanism in sol-gel transition of alginate solutions by addition of divalent cations, Carbohyd. Res. 302 (1997) 97-101, http://dx.doi.org/10.1016/S0008-6215(97)00114-6

[17] C.D. Saquing, C. Tang, B. Monian, C.A. Bonino, J.L. Manasco, E. Alsberg, S.A. Khan, Alginate-Polyethylene Oxide Blend Nanofibers and the Role of the Carrier Polymer in Electrospinning, Ind. Eng. Chem. Res. 52 (2013) 8692-8704, http://dx.doi.org/10.1021/ie302385b

[18] N. Bhattarai, Z. Li, D. Edmondson, M. Zhang, Alginate-Based Nanofibrous Scaffolds: Structural, Mechanical, and Biological Properties, Adv. Mater. 18 (2006) 1463-1467, http://dx.doi.org/10.1002/adma.200502537

[19] W.-W. Hu, H.-N. Yu, Coelectrospinning of chitosan/alginate fibers by dual-jet system for modulating material surfaces, Carbohyd. Polym. 95 (2013) 716-727.

[20] C.A. Bonino, K. Efimenko, S.I. Jeong, M.D. Krebs, E. Alsberg, S.A. Khan, Three-Dimensional Electrospun Alginate Nanofiber Mats via Tailored Charge Repulsions, Small 8 (2012) 1928-1936, http://dx.doi.org/10.1002/smll.201101791

[21] J.-W. Lu, Y.-L. Zhu, Z.-X. Guo, P. Hu, J. Yu, Electrospinning of sodium alginate with poly(ethylene oxide), Polymer $47 \quad$ (2006) 8026-8031, http://dx.doi.org/10.1016/j.polymer.2006.09.027

[22] B. Narayan, Z. Miqin, Controlled synthesis and structural stability of alginatebased nanofibers, Nanotechnology 18 (2007) 455601, http://dx.doi.org/10.1088/0957$\underline{4484 / 18 / 45 / 455601}$

[23] D. Fang, Y. Liu, S. Jiang, J. Nie, G. Ma, Effect of intermolecular interaction on electrospinning of sodium alginate, Carbohyd. Polym. 85 (2011) 276-279, http://dx.doi.org/10.1016/j.carbpol.2011.01.054 
[24] G.C. Anyfantis, M. Scotto, A. Scarpellini, F. Pignatelli, S.M. Toussi, R. Ruffilli, L. Martiradonna, A. Athanassiou, Synergistic Action of Alginate Chemical Reduction and Laser Irradiation for the Formation of $\mathrm{Au}$ Nanoparticles with Controlled Dimensions, Part. Part. Syst. Charact. $32 \quad$ (2015) 389-397, http://dx.doi.org/10.1002/ppsc.201400172

[25] E. Mele, G.C. Anyfantis, D. Fragouli, R. Ruffilli, A. Athanassiou, Localized synthesis of gold nanoparticles in anisotropic alginate structures, RSC Adv. 4 (2014) 20449-20453, http://dx.doi.org/10.1039/C4RA02183E

[26] E. Torres, Y.N. Mata, M.L. Blázquez, J.A. Muñoz, F. González, A. Ballester, Gold and Silver Uptake and Nanoprecipitation on Calcium Alginate Beads, Langmuir, 21 (2005) 7951-7958, http://dx.doi.org/10.1021/la046852k

[27] J. Vincent, B. Roberta, L. David, S. Nathalie, C. Thibaud, In situ growth of gold colloids within alginate films, Nanotechnology, $21 \quad$ (2010) 185605, http://dx.doi.org/10.1088/0957-4484/21/18/185605

[28] C. Sartori, D.S. Finch, B. Ralph, K. Gilding, Determination of the cation content of alginate thin films by FTi.r. spectroscopy, Polymer, 38 (1997) 43-51, http://dx.doi.org/10.1016/S0032-3861(96)00458-2

[29] M.A.K.L. Dissanayake, R. Frech, Infrared Spectroscopic Study of the Phases and Phase Transitions in Poly(ethylene oxide) and Poly(ethylene oxide)-Lithium Trifluoromethanesulfonate Complexes, Macromolecules, 28 (1995) 5312-5319, http://dx.doi.org/10.1021/ma00119a022

[30] M. Borgogna, G. Skjåk-Bræk, S. Paoletti, I. Donati, On the Initial Binding of Alginate by Calcium Ions. The Tilted Egg-Box Hypothesis, J. Phys. Chem. B 117 (2013) 7277-7282, http://dx.doi.org/10.1021/jp4030766 
[31] P. Sikorski, F. Mo, G. Skjåk-Bræk, B.T. Stokke, Evidence for Egg-BoxCompatible Interactions in Calcium-Alginate Gels from Fiber X-ray Diffraction, Biomacromolecules, 8 (2007) 2098-2103, http://dx.doi.org/10.1021/bm0701503

[32] I.V. Mironov, E.V. Makotchenko, The Hydrolysis of $\mathrm{AuCl}_{4}-$ and the Stability of Aquachlorohydroxocomplexes of Gold(III) in Aqueous Solution, J Solution Chem. 38 (2009) 725-737, http://dx.doi.org/10.1007/s10953-009-9400-9

[33] L. Longenberger, G. Mills, Formation of Metal Particles in Aqueous Solutions by Reactions of Metal Complexes with Polymers, J. Phys. Chem. 99 (1995) 475-478, http://dx.doi.org/10.1021/j100002a001

[34] P. Alexandridis, Gold Nanoparticle Synthesis, Morphology Control, and Stabilization Facilitated by Functional Polymers, Chem. Eng. Tech. 34 (2011) 15-28, http://dx.doi.org/10.1002/ceat.201000335

[35] J.P. Soares, J.E. Santos, G.O. Chierice, E.T.G. Cavalheiro, Thermal behavior of alginic acid and its sodium salt, Eclética Química 29 (2004) 57-64, http://dx.doi.org/10.1590/S0100-46702004000200009 